\title{
Bir Kafes Sistemli Yumurta Tavuğu Kümesinde Aydınlatma Yeterliliğinin Standartlara göre Belirlenmesi ve Değerlendirilmesi: Bursa Örneği
}

\author{
Büşra Yaylı ${ }^{1 *}$, İlker Kılıç² \\ 1* Bursa Uludağ Üniversitesi, Ziraat Fakültesi, Biyosistem Mühendisliği Bölümü, Bursa, (ORCID: 0000-0002-0198-3550), busrayayli@uludag.edu.tr \\ ${ }^{2}$ Bursa Uludağ Üniversitesi, Ziraat Fakültesi, Biyosistem Mühendisliği Bölümü, Bursa, (ORCID: 0000-0003-0087-6718), ikilic@uludag.edu.tr
}

(İlk Geliş Tarihi 12 Ekim 2021 ve Kabul Tarihi 6 Aralık 2021)

(DOI: 10.31590/ejosat.1008508)

ATIF/REFERENCE: Yaylı, B. \& İlker, K. (2021). Bir Kafes Sistemli Yumurta Tavuğu Kümesinde Aydınlatma Yeterliliğinin Standartlara göre Belirlenmesi ve Değerlendirilmesi: Bursa Örneği. Avrupa Bilim ve Teknoloji Dergisi, (31), 475-480.

\begin{abstract}
$\ddot{O} \mathbf{z}$
Türkiye'de kümes hayvancılığı üretimi önemli bir hayvancılık koludur. Hayvan yetiştiriciliğinde hayvanların genetik kapasitesi \%30 oranında etkili iken, çevresel etmenler \% 70 oranında etkilidir. Tavuklar bulundukları çevre koşullarına karşı hassas hayvanlar olduğu için diğer türlere göre $1 s ̧ 1 \mathrm{k}$, nem, sıcaklık vb. gibi koşullardan daha çabuk etkilenmektedirler. Kümes içerisinde yeterli düzeyde yapılan aydınlatma, tavukların fizyolojik fonksiyonlarını düzenler, yumurta kalitesini arttırır ve davranışlarını olumlu yönde etkilemektedir. Yeterli aydınlatmanın olmaması tavuklarda huzursuzluk ve verim düşüklüğüne neden olmaktadır. Ayrıca kümeste çalışanlar için de aydınlatma düzeyinin kaza riski oluşturmayacak şekilde yeterli görsel yeterliliğin sağlanması gerekmektedir. Yapılan çalışmada, Bursa bölgesinde faaliyet gösteren bir yumurta tavuğu işletmesinin aydınlatma düzeyinin belirlenmesi ve standartlara göre değerlendirilmesi amaçlanmıştır. İncelenen işletmede, hem doğal aydınlatma hem de yapay aydınlatma yapılmaktadır. Doğal aydınlatma sisteminde kullanılan pencerelerin ve kapıların boyutları ölçülüp kümes taban alanına oranlanmıştır. Kümeste kullanılan yapay aydınlatma sisteminin ışık şiddeti hesabı 1şık akısı yöntemiyle yapılmıştır. Bulgulara göre doğal aydınlatma sisteminin yeterli olduğu fakat günün karanlık saatlerinde rutin işlerin gerçekleştirilebilmesi için yapay aydınlatmaya ihtiyaç duyulduğu belirlenmiştir. Kümeste kafes katlarına göre aydınlık şiddetleri I. katta (alt) 21.7 lx, II. katta 23.1 lx ve III. katta (üst) 23.1 lx olarak saptanmıştır. Kümeste mevcut aydınlatma gücü $2.4 \mathrm{~W} / \mathrm{m}^{2}$ olup gün boyunca 16 saat aydınlatma yapılmaktadır. Literatüre göre kıyaslandığında kümesteki aydınlatma düzeyinin yeterli olduğu söylenebilir.
\end{abstract}

Anahtar Kelimeler: Aydınlatma, Kümes, Hayvan refahı, Enerji tüketimi, İş güvenliği.

\section{Determination and Evaluation of Lighting Sufficiency in a Laying Hens House with Cage System According to Standards: Bursa Example}

\begin{abstract}
Poultry production is an important livestock animal in Turkey. In livestock production, the genetic capacity of animals is $30 \%$ effective and environmental factors are $70 \%$ effective. Chickens are sensitive animals to environmental conditions. Therefore, compared to other livestock species, light, humidity, temperature, etc. are more susceptible to such conditions. Sufficient lighting in the laying hens regulates the physiological functions of chickens, increases egg quality and affects their behavior positively. Otherwise, it causes discomfort and low productivity in laying hen. Moreover, it is necessary to ensure sufficient visual adequacy of the lighting level that will not create an accident risk for the workers in the hen house. This study aimed to determine the lighting level
\end{abstract}

*Sorumlu Yazar: busrayayli@uludag.edu.tr 
of a laying hen house operating in the Bursa region and evaluate it according to the standards. In the monitored farm in this study, both natural and artificial lighting are provided. The windows and doors dimensions used in the natural lighting system were measured and proportioned to the hen floor area. The light intensity calculation of the artificial lighting system used in the hen house was made by the light flux method. According to the findings, it was determined that the natural lighting system was sufficient, but needed artificial lighting was required to carry out routine works in the dark hours of the day. In the hen house, the lighting intensities of cage floors were determined $21.7 \mathrm{~lx}$ on the first floor (bottom), the second floor is $23.1 \mathrm{~lx}$, and the third floor (top) is $23.1 \mathrm{~lx}$. The current lighting power in the hen house is $2.4 \mathrm{~W} / \mathrm{m}^{2}$ and lighting is provided for 16 hours during the day. When compared with the literature, it can say that the hen house lighting level is sufficient.

Keywords: Lighting, Poultry, Animal welfare, Energy consumption, Occupational safety.

\section{Giriş}

Hayvan yetiştiriciliğinde genetik kapasitenin artırılması yönündeki çalışmaların yanı sıra barınak içerisindeki çevresel ve fiziksel faktörler de hayvanların sağlıklarının korunması ve verimliliklerinin artırılması için dikkate alınmalıdır. Hayvansal üretimin kaliteli ve verimlilik düzeyinde hayvan genotipi $\% 30$ etkiliyken, çevresel koşullar \%70 oranında etkilidir (Olgun, 2016). Çevresel koşulların bozulduğu ya da dengesinin sağlanamadığı durumlarda barınaklardaki hayvanların da fizyolojik dengelerinin bozulmasına ve verimliliklerinin düşmesine neden olmaktadır. Aydınlatma da hayvanlar üzerinde önemli etkiye sahip fiziksel faktörlerden birisidir.

Aydınlatma, kümes hayvanlarının davranışlarını, sağlığını, üretkenlik performansını ve yumurta kalitesini etkilediği için fizyolojik fonksiyonlarının kontrol edilmesini sağlayan önemli bir çevresel faktördür (Barros ve ark., 2020). Tavuklar 1şı̆̆a duyarlı, hassas hayvanlardır. Aydınlatma ile ışık uyarısı üreme sistemlerinin fizyolojisi üzerinde olumlu etki göstererek yumurta üretiminin devamlılı̆̆ı için gerekli hormonların salgılanmasını tetiklemektedir (Etches, 1994; Verza ve ark., 2017).

Kümeslerde gündüz aydınlatmasının sağlanması için öncelikle doğal aydınlatmadan yararlanılır. Ancak yetersiz olduğu durumlarda hayvanlar için en uygun koşulların sağlanabilmesi amacıyla yapay aydınlatmadan yararlanılmaktadır. Doğal aydınlatmada pencere alanlarının kümes taban alanına oranı iyi bir ölçüt olarak kullanılmaktadır. Kümeslerde, kümes taban alanının soğuk bölgelerde 1/20'si, 1lık bölgelerde $1 / 10$ 'u ve sicak bölgelerde ise $1 / 5$ 'i kadar toplam pencere alanı bırakılmalıdır (Olgun, 2016). Ayrıca, barınak içerisinde pencere alanlarının barınak taban alanına oranının soğuk bölgelerde $\% 3.5$, 1lık bölgelerde $\% 5$ ve sıcak bölgelerde \%10 olması önerilmektedir (Ekmekyapar, 1993).

Aydınlatma yapılırken aydınlatmanın kalitesini düşürmeden, enerji tasarrufu sağlayan ve daha verimli aydınlatma elemanları kullanılarak iyi bir aydınlatmanın şartları yerine getirilmelidir (Y1lmaz ve Sungur, 2020). Kümeslerde yapay aydınlatma yapılması gereken koşullarda doğru ve yeknesak bir aydınlatma yapılması için 1şığın kaynağı, dalga boyu, şiddeti, yoğunluğu, rengi, spektral dağılımı, aydınlatma süresi, lambaların mekânsal dağılımı vb. gibi birçok faktöre dikkat edilmesi gerekmektedir (Pereira ve ark., 2012). Kümeslerde aydınlatma amacıyla akkor ampüller, kompakt floresan lambalar (CFL), soğuk katot floresan lambalar (CCFL), ledler, tüp floresanlar, yüksek yoğunluklu deşarj lambalar (HID) ve yüksek basınçlı sodyum lambalar (HPS) gibi aydınlatma seçenekleri kullanılabilmektedir (Harmon ve Petersen, 2011). Ekmekyapar'a (1993) göre kümeslerde kümesin taban alanının her $20 \mathrm{~m}^{2}$ 'si için en az 40 W'lık lambalar kullanılmalıdır.
Yumurtacı Tavukların Korunması İle İlgili Asgari Standartlara İlişkin Yönetmeliğe göre tavukların birbirlerini görmelerine, açıkça etraflarını araştırabilmelerine ve doğal davranışlarını gerçekleştirebilecek imkân sağlayacak yeterlilikte aydınlatma seviyesi sağlanmalıdır (Yumurtacı Tavukların Korunması İle İlgili Asgari Standartlara İlişkin Yönetmelik, 2014). Yönetmelikte önerilen belirli bir aydınlatma şiddeti yer almamaktadır. Fakat günün aydınlatma saatleri 24 saatlik bir ritmi takip etmeli ve bir günün 8 saatinden az olmayacak şekilde devamlı bir karanlık periyot sağlanması gerektiği belirtilmektedir.

Kümeslerde hayvanların refahı açısından da Çiftlik Hayvanlarının Refahına İlişkin Genel Hükümler Hakkında Yönetmeliğe göre fizyolojik ve etolojik ihtiyaçlarının karşılanması için doğal aydınlatma yetersiz ise ve yapay aydınlatma yapılacaksa doğal 1şık süresine eşdeğer süre için uygun 8 saatlik aydınlatma sağlanması gerekmektedir (Çiftlik Hayvanlarının Refahına İlişkin Genel Hükümler Hakkında Yönetmelik, 2014).

Barınaklar içerisinde hayvanların verimli ve sağlıklı yetiştirilebilmeleri için ortam koşullarının önemli olmasının yanı sıra çalışan insanların da güvenli ve sağlıklı bir ortamda çalışmaları çok önemli bir konudur. Kümes hayvanı yetiştiriciliğinde eğer gerekli önlemler alınmazsa çalışanlarda bazı sağlık problemleri ortaya çıkabilmektedir ve bunların önlenmesi için kümeslerde yeterli aydınlatma sağlanmalıdır (Demirhan ve ark., 2016).

İşyeri Bina ve Eklentilerinde Alınacak Sağlık ve Güvenlik Önlemlerine İlişkin Yönetmeliğe göre işyerlerinde gün 1şığıyla yeterli düzeyde aydınlatılmış olması esas alınmaktadır. Gün 1şı̆̆ının yetersiz geldiği ya da gece çalışma durumlarında, yapay aydınlatmanın en uygun şekilde sağlanması gereklidir ve bunun için TS EN 12464-1: 2013, TS EN 12464-1:2011: 2012; standartları esas alınmaktadır (İşyeri Bina ve Eklentilerinde Alınacak Sağlık ve Güvenlik Önlemlerine İlişkin Yönetmelik, 2013).

$\mathrm{Bu}$ çalışmada, Bursa bölgesinde faaliyet gösteren bir yumurta tavuğu kümesinin aydınlatma düzeyinin belirlenmesi ve aydınlatma verimliliğinin çeşitli standart ve yönetmelikler ile karşılaştırılması ve değerlendirilmesi amaçlanmaktadır.

\section{Materyal ve Metot}

Çalışmada Bursa bölgesinde faaliyet gösteren ticari bir kafes sistemli yumurta tavuğu kümesinin aydınlık düzeyinin yeterliliği, tavukların refahı ve iş sağlı̆̆ı güvenliği esasları çerçevesinde incelenmiştir. Kümeste hem doğal aydınlatma hem de yapay aydınlatma yapılmaktadır. Kümeste doğal aydınlatma her her iki uzun kenarda bulunan 4 adet toplamda 8 adet pencere 
ile yapılmaktadır. Ayrıca işletme içerisinde kümesin sonunda bulunan iki adet havalandırma fanı ve sürekli açık duran bir kapısı bulunmaktadır. Bunlar da doğal aydınlatmayı desteklediği için hesaplamalarda bu açıklıklar da dikkate alınmıştır (Şekil 1).

Kümes $360 \mathrm{~m}^{2}$ lik alana sahiptir ve 5 kafes sırası ile 4 koridor bulunmaktadır (Şekil 2). Her bir koridorda 10 adet, kümes girişinde ise 4 adet toplamda 44 adet bulunan Led floresan ile aydınlatma yapılmaktadır. Led lambaların kümes

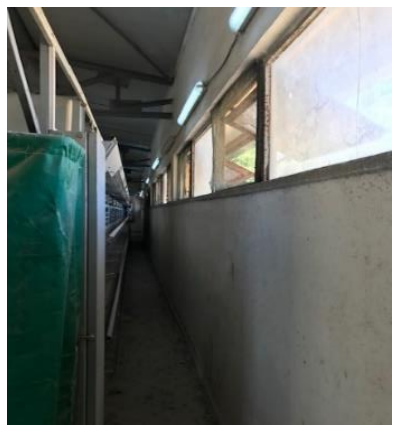

$\mathbf{a}$

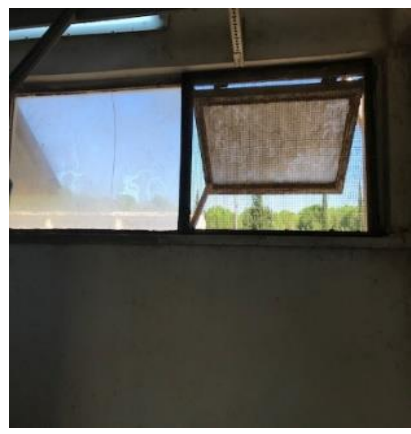

b

içerisindeki yerleşimleri Şekil 2'de verilmiştir. Floresanların her biri $20 \mathrm{~W}$ gücündedir. Sabah 6.30'dan akşam 10:30'a kadar devamlı aydınlatma yapılarak günde 16 saat yapay aydınlatma yapilmaktadir.

Kümeste doğal aydınlatma hesaplaması kullanılan pencere ve kapıların kümes taban alanına oranlanmasıyla gerçekleştirilmiştir. Yapay aydınlatma sisteminde 1 şık şiddeti ve aydınlatma gücü ise 1 şı akısı yöntemiyle hesaplanmıştır.

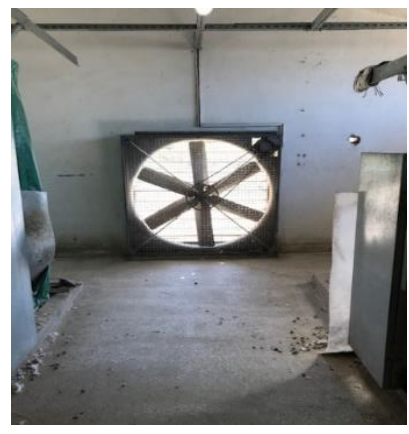

c

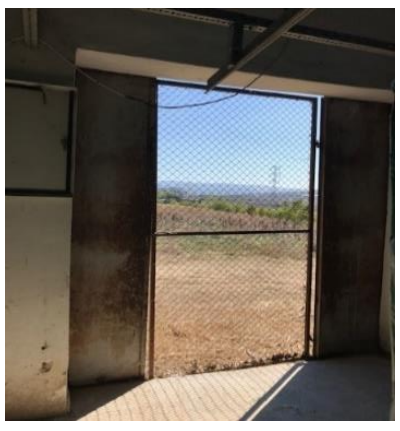

d

Şekil 1. Incelenen kümeste doğal aydınlatma için kullanılan açıklıklar (a,b: pencere, c: havalandırma fanı, d: kapı)

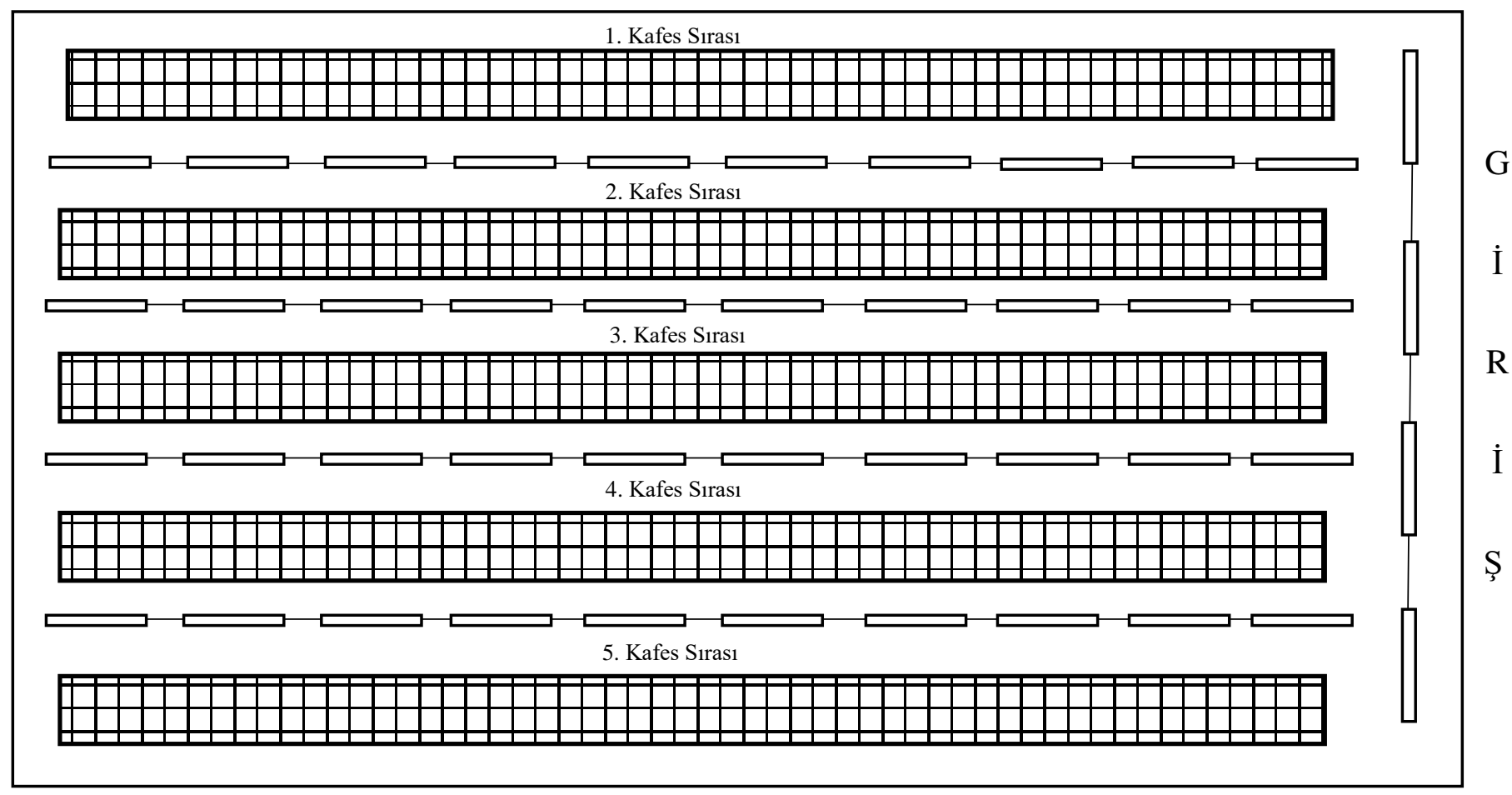

Şekil 2. İşletmede lambaların yerleşim planı

\section{Araştırma Sonuçları ve Tartışma}

\subsection{Aydınlatma Sisteminin Özellikleri}

Araştırmanın gerçekleştirildiği kümes içerisinde doğal aydınlatma, kümes boyunca karşılıklı olarak yer alan 5.4 x 0.75 m boyutlarındaki toplamda 8 adet pencere ile sağlanmaktadır. Pencereler kümes tabanından 1.75 m yükseklikte bulunmaktadır.
Ayrıca iki adet $0.68 \mathrm{~m}$ çapında havalandırma fanı ve 1.34 x 2.6 boyutlarındaki kapı alanları Tablo 1'de verilmiştir.

Tablo 1'e göre kümesteki açıklık alanlarının kümes taban alanına oranı yaklaşık \%11'dir. $\mathrm{Bu}$ değer literatür ile karşılaştırıldığında doğal aydınlatma gündüz vakti kümesteki gündelik işlerin yapılabilmesi için yeterlidir. Ancak günün karanlık saatlerinde kümesteki rutin işlerin yürütülebilmesi için yapay aydınlatmaya da gereksinim duyulmaktadır. Kümeslerde 
doğal aydınlatma yapılırken pencere alanlarının yetersiz kalması tavukların fizyolojik faaliyetlerini olumsuz etkilemekte ve verim kaybına neden olmaktadır. Pencere alanlarının gereğinden fazla olması durumunda ise kış mevsiminde 1Sı kayıpları daha fazla olacağından 1sı dengesinin oluşturmasını zorlaştıracaktır (Kocaman, 2010).

Tablo 1. Işsletme içerisindeki aydınlatma açıklıklarının boyutları

\begin{tabular}{cccccc}
\hline $\begin{array}{c}\text { Toplam pencere alanı } \\
\left(\mathbf{m}^{\mathbf{2}}\right)\end{array}$ & $\begin{array}{c}\text { Kapı alanı } \\
\left(\mathbf{m}^{\mathbf{2}}\right)\end{array}$ & $\begin{array}{c}\text { Toplam fan } \\
\text { alanı }\left(\mathbf{m}^{\mathbf{2}}\right)\end{array}$ & $\begin{array}{c}\text { Toplam açıklık alanı } \\
\left(\mathbf{m}^{\mathbf{2}}\right)\end{array}$ & $\begin{array}{c}\text { Kümes taban } \\
\text { alanı }\left(\mathbf{m}^{\mathbf{2}}\right)\end{array}$ & $\begin{array}{c}\text { Açıklık/Kümes } \\
\text { taban alan oranı }\end{array}$ \\
\hline 32.4 & 3.48 & 2.9 & 38.78 & 360 \\
\hline
\end{tabular}

\subsection{Hayvan Refahı Açısından Aydınlatma}

Çalışmanın gerçekleştirildiği işletmede kafes sıraları 3 katlıdır ve kümeste yapılan yapay aydınlatma sistemine ait görüntüler Şekil 3'te verilmiştir. Her bir kat için lambaların aydınlatma verimleri ayrı ayrı hesaplanmıştır. Buna göre en alt katta aydınlatma verimi $\% 49.3$, orta katta $\% 52.5$ ve en üst katta $\% 53$ olarak hesaplanmıştır. Kümeste yapılan mevcut aydınlatma gücü $2.4 \mathrm{~W} / \mathrm{m}^{2}$ 'dir (Tablo 2). Literatürde yumurta tavuğu kümesleri için yapay aydınlatmada $2-3 \quad \mathrm{~W} / \mathrm{m}^{2}$ olarak önerilmektedir (Şenköylü, 2001; Kocaman, 2010). Kümesteki yapay aydınlatma değeri önerilen değerler arasında kalmaktadır. İşletme içerisinde bulunan mevcut aydınlatıcı sayısı 44 adettir. Işık akısı yöntemiyle yapılan hesaplamalara göre bu işletmede
40 adet lamba ile yapılacak aydınlatma da yeterli olabileceği hesaplanmıştır. Aydınlatmanın tavuklar üzerinde verim üzerine yapılmış çeşitli çalışmalar bulunmaktadır. Tavuklarda yüksek aydınlatma seviyeleri hayvanlarda hareketliliği, gagalama ve kanibalizmi artırmasının yanı sıra aktivitenin artmasıyla ortamdaki tozluluğun da artması verim düşüklüğüne neden olabilmektedir (Kristensen ve ark., 2006). Yumurtacı Tavukların Korunması İle İlgili Asgari Standartlara İlişkin Yönetmenliğe göre kümeste yapılan 16 saatlik aydınlatma ardından 8 saatlik devamlı karanlık periyodu gerçekleştirerek yumurtacı tavukların aydınlıktan korunması sağlanmaktadır. Çiftlik Hayvanlarının Refahına İlişkin Genel Hükümler Hakkındaki Yönetmeliğe göre en az 8 saat aydınlatması yapılması hayvan refahını koruması açısından da koşulları sağlamaktadır.

Tablo 2. Kümes ile ilgili yapay aydınlatma bilgileri

\begin{tabular}{ccccc}
\hline Kafes Katları & $\begin{array}{c}\text { Aydınlatma verimi } \\
(\boldsymbol{\%})\end{array}$ & $\begin{array}{c}\text { Mevcut aydınlık şiddeti } \\
(\mathbf{l x})\end{array}$ & $\begin{array}{c}\text { Gerekli aydınlatıcı } \\
\text { sayısı (20 W'lk) }\end{array}$ & $\begin{array}{c}\text { Mevcut aydınlatma gücü } \\
\left(\mathbf{W} / \mathbf{m}^{\mathbf{2}}\right)\end{array}$ \\
\hline I & 49.3 & 21.7 & 40 & 2.4 \\
\hline II & 52.5 & 23.1 & 40 & 2.4 \\
\hline III & 53.0 & 23.1 & 40 & 2.4 \\
\hline
\end{tabular}

I: 1.kat (alt), II: 2. Kat, III: 3. kat (üst)
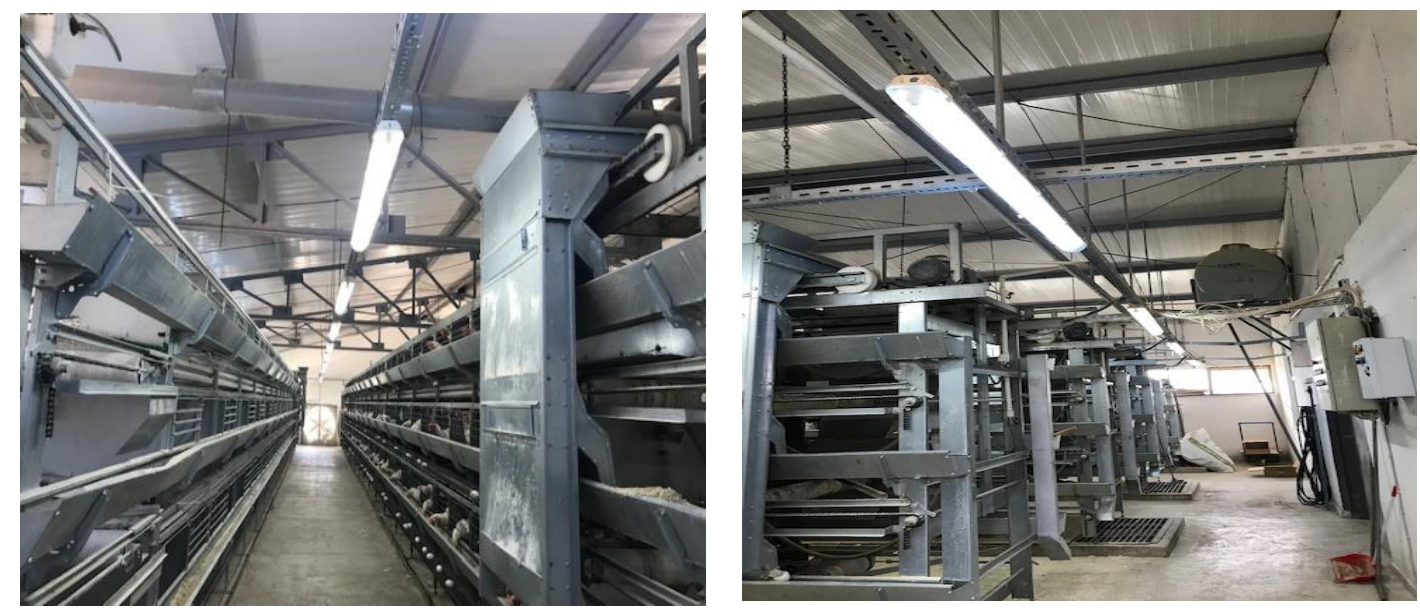

Şekil 3. Incelenen kümes içerisinde yapay aydınlatma görüntüleri 


\subsection{Standartlara Göre Aydınlatma Sistemleri}

Ülkemizde standartları belirleyen kuruluş olan Türk Standartları Enstitüsü endüstriyel faaliyetler için aydınlatma standartlarını belirlemişlerdir. TS EN 12464-1 Işı ve Aydınlatma - Çalışma Yerlerinin Aydınlatılması - Bölüm 1: Kapalı Çalışma Alanları (Light and lighting - Lighting of work places - Part 1: Indoor work places) standardına göre endüstriyel faaliyetler içerisinde tarım sektörü kapalı çalışma ortamları için bazı değerler yer almaktadır (TS EN 12464-1, 2013) (Tablo 3). Standart maddelerine göre hayvan barınakları canlı hayvanlar için binalar başlığı altına girmektedir. Bu başlığa göre hayvanlar için gerekli aydınlatma şiddeti 50 lx olarak verilmiştir. İncelenen işletmede uygulanan aydınlatma şiddeti 23 lx olarak gerçekleştiğinden dolayı belirtilen sınır değerinin altında gerçekleşmiştir. $\mathrm{Bu}$ durumda incelenen işletmenin aydınlatma sistemi TSE EN 12464-1 standardını sağlamamaktadır.

Avrupa Birliğine katılan ülkelerde uygulanan aydınlatma yönetmeliği EN standardıdır. Bu standart ülkemizde uygulanan TSE EN 12464-1 standardı ile benzerdir. Avrupa Birliği'ne katılım sürecinde açılan başlıklardan biri olması nedeniyle bu yönetmelik Türkçeye çevrilerek doğrudan ülkemizde uygulanmaktadir.

Tablo 3. TS EN 12464-1 tarım faaliyetlerine göre aydınlatma özellikleri

\begin{tabular}{lcccc}
\hline İç kısım, İş veya Faaliyet Tipi & $\mathbf{E}_{\mathbf{m}} \mathbf{( l \mathbf { x } )}$ & $\mathbf{U G R}_{\mathbf{L}}$ & $\mathbf{U}_{\mathbf{o}}$ & $\mathbf{R}_{\mathbf{a}}$ \\
\hline $\begin{array}{l}\text { Ürünlerin yüklenmesi ve çalıştırılması, kullanma tesisatı ve } \\
\text { düzeneği }\end{array}$ & 200 & 25 & 0.40 & 80 \\
\hline Canlı hayvanlar için binalar & 50 & - & 0.40 & 40 \\
\hline Hasta hayvan kafesleri; yavrulama ahırları & 200 & 25 & 0.60 & 80 \\
\hline Besin hazırlama; mandıra; kap yıkama & 200 & 25 & 0.60 & 80 \\
\hline
\end{tabular}

$\mathrm{E}_{\mathrm{m}}$ : İş veya faaliyet için referans yüzeydeki sürdürülen ortalama aydınlatma yoğunluğu

UGR $_{\mathrm{L}}$ : Birleşik Göz Kamaşması Değer Sınırı

$\mathrm{U}_{\mathrm{o}}$ : Minimum aydınlatma homojenliği

$\mathrm{R}_{\mathrm{a}}$ : renksel geri verim

Amerika Birleşik Devletlerinde ASABE (American Society of Agricultural and Biological Engineers), tarımsal faaliyetlerdeki aydınlatma sistemleri için standartlar belirlemiştir. Tablo 4'te kümes hayvanları için büyüme dönemlerine göre aydınlatma kılavuzu verilmiştir (ASABE, 2005). İncelenen kümesteki yumurta tavukları 48 haftalıktır ve buna göre ASABE standartlarına göre minimum 5-10 lx arasında aydınlatma yapılması gereklidir. İşletmede en alt kat için aydınlatma şiddeti 17.3 lx, orta kat için 18.3 lx ve en üst kat için 19.1 lx olarak ölçülmüştür. Standartlara göre işletme içerisinde yapılan aydınlatma şiddeti minimum değerlerin biraz üzerindedir. Ayrıca Tablo 4'e göre gün içerisinde yapılan 15 saatlik aydınlatma yeterli iken işletmede 16 saat aydınlatma yapılmaktadır. Buradan kümes içerisinde yapılan aydınlatmanın gereğinden fazla enerji tüketimine neden olduğu söylenebilmektedir.

Tablo 4. ASABE standartlarl (ASABE, 2005)

\begin{tabular}{cccc}
\hline $\begin{array}{c}\text { Kümes } \\
\text { hayvanı } \\
\text { türü }\end{array}$ & $\begin{array}{c}\text { Yaş } \\
\text { (Hafta) }\end{array}$ & $\begin{array}{c}\text { Minimum Işık } \\
\text { Şiddeti (lx) }\end{array}$ & $\begin{array}{c}\text { Fotoperiyot } \\
\text { (saat/gün) }\end{array}$ \\
\hline Yumurta & $0-6$ & $10-30$ & 16 \\
Tavuğu & $6-18$ & $5-10$ & 8 \\
\hline \multirow{2}{*}{ Broyler } & $18-80$ & $5-10$ & 15 \\
\hline \multirow{3}{*}{ Damılılk } & $0-2.5$ & $20-30$ & 24 \\
& $2.5-k e s i m$ & $5-10$ & 24 \\
\hline
\end{tabular}

\section{4. İş Sağlığı Güvenliği Açısından Aydınlatma}

Aydınlatma düzeyi, çalışan insanlar için tehlikeleri fark edebilmesi ve görsel yetersizliğe bağlı kazaların olmaması için iş ortamında yeterli düzeyde olmalı ve ortamda homojen bir şekilde dağılması gerekmektedir. Aksi takdirde aydınlatma

yoğunluklarındaki büyük değişiklikler çalışanlarda görsel rahatsızlıklara ve strese neden olabilmektedir. TS EN 12464-1 standardına göre yakın çevreleyen alanların aydınlatma yoğunluğu iş alanının aydınlatma yoğunluğuyla ilişkili olmalı ve görüş sahasında iyi dengelenmiş bir 1şık yoğunluğu dağılımı sağlamalıdır. Yakın çevreleyen alan görüş alanındaki iş alanının etrafinda en az $0.5 \mathrm{~m}$ genişliğinde bir bant olmalıdır (TS EN 12464-1, 2013). İncelenen işletmede çalışanlar için bu mesafe sağlanmaktadır fakat Tablo 5'teki değerler ile kıyaslandığında işletmedeki aydınlık şiddeti yetersiz kalmaktadır.

Tablo 5. TS EN 12464-2 tarım faaliyetlerine göre aydınlatma özellikleri (TS EN 12464-2, 2014)

\begin{tabular}{lcccc}
\hline İş veya Faaliyet Tipi & $\mathbf{E}_{\mathbf{m}}(\mathbf{l x})$ & $\mathbf{U}_{\mathbf{o}}$ & $\mathbf{R}_{\mathbf{G L}}$ & $\mathbf{R}_{\mathbf{a}}$ \\
\hline Çiftlik alanı & 20 & 0.10 & 55 & 20 \\
\hline Ekipman odası (açık) & 50 & 0.20 & 55 & 20 \\
\hline Hayvan durakları & 50 & 0.20 & 50 & 40 \\
\hline
\end{tabular}

$\mathrm{E}_{\mathrm{m}}$ : İş veya faaliyet için referans yüzeydeki sürdürülen ortalama aydınlatma yoğunluğu

$\mathrm{R}_{\mathrm{GL}}$ : Parlama derecesi sinırı

$\mathrm{U}_{\mathrm{o}}$ : Minimum aydınlatma homojenliği

$\mathrm{R}_{\mathrm{a}}$ : renksel geri verim

\subsection{Aydınlatma Sisteminin Enerji Tüketimi}

$\mathrm{Bu}$ kapsamda işletme içerisinde enerji tüketiminin işletme ölçeğinde yeterli olduğu söylenebilir. Aydınlatma kümeslerde enerji tüketimini azaltmada önemli bir faktördür ve kanatlı üretim sistemlerinde yemden sonra en kritik ikinci girdiyi oluşturmaktadır (Pereira ve ark., 2012). Yapılan bir çalışmada, kümeste kış döneminde 40 gün boyunca tüketilen toplam enerjinin \%55'inin aydınlatma sisteminden kaynaklandığını belirtilmiştir (Turco ve ark., 2002). LED ampullerin enerji tüketimlerinin düşük olması, yüksek aydınlatma verimine sahip olması ve arızalanma oranlarının düşük ve bakım maliyetlerinin düşük olmasıyla iyi bir alternatiftir. 


\section{Sonuç}

Bu çalışmada, bir yumurta tavuğu kümesi içerisinde kurulu olan aydınlatma sisteminin yeterliliği üzerinde durulmaya çalışılmıştır. Ayrıca aydınlatmanın hem hayvanlar hem de insanlar üzerindeki etkileri belirli standartlar dikkate alınarak değerlendirilmesi yapılmıştır. Aydınlatma, kümes içerisinde dikkate alınması gereken ilk etmenlerden birisidir. Yumurtanın oluşumu için ciddi bir rolü vardır. Yumurta veriminin yanı sıra tavukların fizyolojik gelişimleri açısından da önemlidir. Aydınlatma iş kazalarının en aza indirilebilmesi açısından çalışanlar için de optimum düzeyde olması istenir ve ayrıca işçilerde zamanla görsel rahatsızlıklara neden olmaması için önemli bir çevresel faktördür. İşletmelerin kurulması sırasında doğal aydınlatma ve yapay aydınlatma için literatür ve standartlarda verilen oran ve değerlerin dikkate alınarak, yeterli boyutlarda pencere, uygun sayıda armatür ve aydınlatma süresi seçilerek hem yeknesak bir aydınlık sağlanması hem de enerji tüketiminden tasarruf edilmesi önerilmektedir.

\section{Kaynakça}

ASABE, (2005). American Society of Agricultural and Biological Engineers, Lighting Systems for Agricultural Facilities.

Çiftlik Hayvanlarının Refahına İlişkin Genel Hükümler Hakkında Yönetmelik, (2014). İkinci Bölüm, İşletmeler ve işletme içi düzenlenmeler. https://www.resmigazete.gov.tr/eskiler/2014/11/201411226.htm (Erişim Tarihi:24.09.2021).

Demirhan, S. A., Çelen, B., Çelen, M. F., \& Şahinler, N. (2016). Hayvancılıkta İş Sağlığı ve Güvenliği. Nevşehir Bilim ve Teknoloji Dergisi, 5, 303-314. http://dx.doi.org/10.17100/nevbiltek.211015

Ekmekyapar, T., (1993). Hayvan Barınaklarında Çevre Koşullarının Düzenlenmesi, Atatürk Üniversitesi, Ziraat Fakültesi Yayınları, Yayın No: 306, Erzurum.

Etches, R. J. (1994). Estímulo luminoso na reprodução In: Pinheiro, M.R. Fisiologia da Reprodução de Aves pp. 59-75.

Barros J. D. S. G., Barros, T. A. D. S., Sartor, K., Raimundo, J. A., \& Rossi, L. A. (2020). The effect of linear lighting systems on the productive performance and egg quality of laying hens. Poultry science, 99(3), 1369-1378. http://dx.doi.org/10.1016/j.psj.2019.11.007

Harmon, J. D. \& Petersen, D. (2011). "Farm Energy: Indoor lighting for livestock, poultry, and farm shop facilities" Agriculture and Environment Extension Publications. 32. https://lib.dr.iastate.edu/cgi/viewcontent.cgi?article=1024\&c ontext=extension_ag_pubs (Erişim tarihi: 24.09.2021)

İşyeri Bina ve Eklentilerinde Alınacak Sağlık ve Güvenlik Önlemlerine İlişkin Yönetmelik, (2013). Ek-1: işyeri bina ve eklentilerinde uygulanacak asgari sağlık ve güvenlik şartları, Aydinlatma.

https://www.resmigazete.gov.tr/eskiler/2013/07/201307172.htm (Erişim Tarihi: 24.09.2021).

Kocaman, İ. (2010). Karaman ili merkez ilçedeki yumurta tavuğu kümeslerinin yapısal özelliklerinin belirlenmesi ve geliştirilebilme olanaklarının araştırılması. Tekirdă̆ Ziraat Fakültesi Dergisi, 7(2), 179-186.

Kristensen, H.H., Aerts, J.M., Leroy, T., Wathes, C.M. \& Berckmans, D. (2006). Modelling the dynamic activity of broiler chickens in response to step-wise changes in light intensity. Applied Animal Behaviour Science, 101(1-2): 125143. https://doi.org/10.1016/j.applanim.2006.01.007

Olgun, M. (2016). Tarımsal Yapılar. Ankara Üniversitesi Yayınları, Yayın No:1577, Üçüncü Baskı. Ankara.

Pereira, P. A., Yanagi Junior, T., Silva, J. P. D., Lima, R. R. D., Campos, A. T., \& Abreu, L. H. (2012). Technical evaluation of artificial lighting systems for broiler houses. Engenharia Agrícola, 32, 1011-1024. https://doi.org/10.1590/S0100$\underline{69162012000600002}$

Şenköylü, N., (2001). Modern Tavuk Üretimi. Trakya Üniversitesi, Ziraat Fakültesi Yayınları, Yayın No:47, Ders Notu No: 40, Tekirdağ. $358 \mathrm{~s}$.

TS EN 12464-1, (2013). Türk Standartları Enstitüsü, Işık ve Aydınlatma - Çalışma Yerlerinin Aydınlatılması - Bölüm 1: Kapalı Çalışma Alanları.

TS EN 12464-2, (2014). Türk Standartları Enstitüsü, Işık ve aydınlatma - İş yerlerinin aydınlatılması - Bölüm 2: Bina dışı iş yerleri.

Turco, J. E., Ferreira, L. F. \& Furlan, R. L. (2002). Consumo e custo de energia elétrica em equipamentos utilizados em galpão de frangos de corte. Revista Brasileira de Engenharia Agrícola e Ambiental, 6, 519-522. https://doi.org/10.1590/S1415-43662002000300023

Verza, S. P., Peixoto, E. C. T. M., Tamehiro, C. Y., Hasegawa, M. M., Porto, P. P., \& da Silva, M. A. A. (2017). LED in production systems of laying hens: An alternative to increase sustainability. African Journal of Agricultural Research, 12(16), 1379-1384. https://doi.org/10.5897/AJAR2016.11946

Yılmaz, S. \& Sungur, C. (2020). Kamu Binalarında Mevcut Aydınlatma Elemanlarının LED Aydınlatma Elemanlarına Dönüştürülmesi ile Elde Edilecek Elektrik Enerjisi Tasarrufunun Belirlenmesi. Avrupa Bilim ve Teknoloji Dergisi, (Özel Say1), 214-218. https://doi.org/10.31590/ejosat.804281

Yumurtac1 Tavukların Korunmasi İle İlgili Asgari Standartlara İlişkin Yönetmelik, (2014). Üçüncü Bölüm, Aydınlatma. https://www.resmigazete.gov.tr/eskiler/2014/11/201411227.htm (Erişim Tarihi: 24.09.2021). 